\title{
IMPACT OF HORIZONTAL CURVES AND PERCENTAGE OF HEAVY VEHICLES ON RIGHT LANE CAPACITY AT MULTI-LANE HIGHWAYS
}

\begin{abstract}
In the present research, the influence of road geometric properties and traffic characteristics on the right lane capacity value is explored for horizontal curves. The non-traditional procedure (artificial neural networks - ANNs), is adopted for modelling. The research utilizes 78 horizontal curves that provide the traffic and road geometry data, of which55 curves are classified as four-lane and the rest as six-lane ones. Two types of models are introduced to explore the right lane capacity as capacity at curves, and the capacity loss between curves and tangents. The results show that, for horizontal curves, the most effective variables affecting both road types are the percentage of heavy vehicles in traffic composition (HV) followed by radius of curve (R), and the lane width (LW). Furthermore, the capacity loss is also highly affected by $R$ followed by HV. The derived outcomes present a remarkable move towards the beginning of an Egyptian highway design guide.
\end{abstract}

\section{KEY WORDS}

multi-lane highway; road geometric properties; traffic characteristics; right lane capacity; artificial neural networks;

\section{INTRODUCTION}

The determination of highway capacity is strongly pertained with two main features; the road geometric design and the traffic flow properties, in particular, for the horizontal alignment. Kerner [1] pointed out that the determination of the highway capacity is one of the most important applications of any traffic theory. Transportation research authorities executed effective efforts in exploring highway capacity. Numerous studies are highly concerned with the relations between speed, density, and capacity on the uninterrupted roadway sections. The American Highway Capacity Manual [2] confirmed that the road capacity is strongly related to the free flow speed. Broadly, the capacity derivation issue is partitioned in two denominations; the direct-empirical and the indirect-empirical methods, Minderhoud et al. [3], of which the direct-empirical method is applicable in the scope here.
However, the main objective of the present research is to calculate multi-lane highway right lane capacity mainly at horizontal curves.

The right lane is a critical lane because it is used by the majority of the traffic especially heavy vehicles. This affects badly the right lane capacity. Therefore, the present study concentrates on this lane.

A developed modelling technique is utilized for this purpose. It is of sophisticated manner as ANNs. Specific field data have been collected on the Egyptian multilane highways. The investigation included 78 curved sections that are located on the main Egyptian multilane highways. Two of these exist in the desert zone (Cairo-Alexandria and Cairo-Ismailia desert highways), and the other two exist in the agricultural zone (Cairo-Alexandria and Tanta-Damietta agricultural roads). The highway cross section occupied by 55 curves is divided into four-lane two-way road, while the section occupied by the other 23 curves is divided into six-lane two-way road. Due to the obvious difference in the geometric characteristics and traffic volumes between the two types of multi-lane highways, a separate analysis has been carried out for every one of them.

Therefore, the analysis of this paper utilizes ANN procedure to investigate the relationships between the right lane capacity per one direction of flow as dependent variable, and the horizontal curve radius $(R)$, roadway factors (i.e. lane width (LW), median width (MW), and lateral clearance (LC)), and percentage of heavy vehicles in traffic composition (HV) as independent variables.

Also, two capacity paradigms have been derived. The first one isthe capacity at midpoint of the curve and the second is the capacity loss between the curves and tangents. The existence of the horizontal curves surely forces the drivers to reduce their speed; consequently, the traffic flow clearly decreases and so, the capacity value of this site will drop significantly, Hashim and Abdel-wahed [4]. However, the results of the present paper can help the Egyptians road responsible to evaluate the right lane capacity of various horizontal curves on Egyptian multi-lane highways and evolve the proper traffic behaviour in the future. 
Many papers have been written to explain the impact of road geometry and traffic composition on the capacity for multi-lane facilities. Kerner [1] affirmed that the computation of capacity for any route is one of the most substantial enforcements of the traffic notion. Various former notions and tentative explorations were concentrated on the mutual relations between the road capacity on the one hand, and the traffic and geometric characteristics on the other hand, along with the uninterrupted multi-lane roads, Iwasaki 1991 [5], Ibrahim and Hall [6], and Shankar and Mannering [7].

Bang et al. [8], in their preparation of the Indonesian design guide, pointed out that the vehicle speed is the main factor in determining road segment capacity.

Yang and Zhang [9] explored the effect of the lane number on the multi-lane road capacity utilizing site traffic flow information which was collected from Beijing. The results indicated that the lane average capacity is reduced by the increment of lane number on the studied highway sections. The minor reduction percent of mean lane capacity by increment of lane number is found to be about $6.7 \%$.

Ben-Edigbe and Ferguson [10], studied the effect of highway state, pavement defects, on the capacity and capacity loss on two-lane roads depending on data collection from eight locations in Nigeria. The capacity computation procedure used the extracted required data from a basic graph indicating the traffic flow-density relationship. The capacities were computed in two adverse cases as without-distress and with-distress road segments. The results showed that a significant difference between the above two capacities were deduced.

Velmurugan et al. [11] examined the relation between the speed and the flow characteristics of different kinds of multi-lane roads in India. Consequently, the capacity of these highways was determined depending on conventional and microscopic emulation paradigms.

Arasan and Arkatkar [12] explained the effect of the inconstancy of traffic installation, route width, and vertical alignments on the multi-lane highway capacity in India. The main conclusion of this research showed that the highway capacity varies considerably with the variation in traffic volume installation, road width, and percentage of the upgrade.

Garcia et al. [13] explored the impact of traffic calming devices on the Spanish road capacity depending on various kinds of devices and spacing between them. It was concluded that the capacity changed among 810 and 1,300 vehicles per hour per lane, according to the calming devices intervals through 25 to 400 meters.

On the local level, there are extremely few studies being interested in this issue because of the scarcity of required data as road geometry, horizontal curve properties, and traffic flow characteristics. The most significant papers on this issue are given here below.

Semeida [14] explained the impact of roadway geometry and traffic properties on the lane capacity at 45 tangent sections existing on four major multi-lane rural roads. He found that the most important factors bearing on the capacity are: the lane width, HV, and side access existence.

Semeida [15] explored the impact of roadway and traffic characteristics on the level of service (LOS) at 78 curved sections that are located on the major Egyptian highways, where the most effective factors on the LOS are found to be: the average annual daily traffic (AADT), HV, and R.

However, the present study is expanded to involve the capacity on the curved sections that are located in the vast area. Also, two major kinds of multi-lanes are explained separately (four-lane two-way and six-lane two-way types), where the current paradigms are appropriate for all the Egyptian multi-lane highways.

\section{BASIC DATA COLLECTION}

\section{Road geometric data}

The present paper focuses on the curved sections on the Egyptian multi-lane facilities. The research utilizes 78 curved sections that are located on the major Egyptian multi-lane roads. The road names are: Cairo-Alexandria Agricultural Highway (CAA), Tanta-Damietta Agricultural Highway (TDA), Cairo-Alexandria Desert Highway (CAD), and Cairo-Ismailia Desert Highway (CID), Figure 1. The selected curved sections are situated in a comparatively plane region to minimize or avert the impact of the vertical slope.

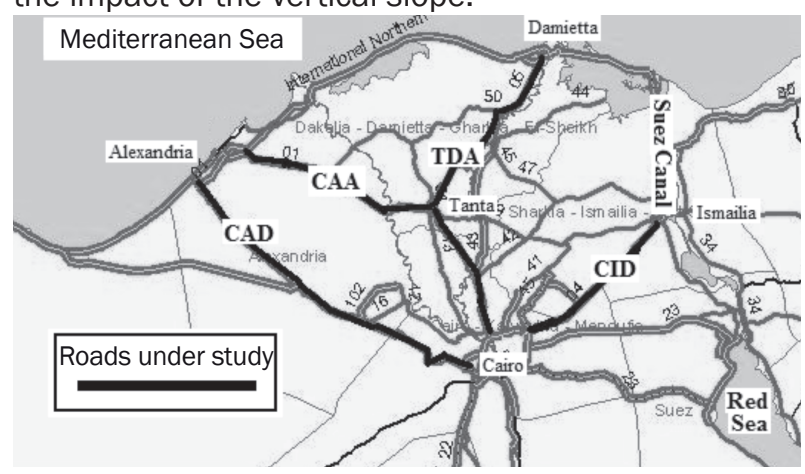

Figure 1 - Multi-lane highways under study on Egyptian roads network

The geometry of roads will supply the basic independent parameters in the research. The lane width (LW), median width (MW), and lateral clearance (LC) are measured at once from the field exploration. The horizontal curve radii $(\mathrm{R})$ are obtained by utilizing the General Authority of Roads, Bridges and Land Transport in Egypt (GARBLT) [16]. The extracted information includes: the curve radius (R), deflection angle (DA), and superelevation (e). All the selected data, their 
Table 1 - Symbols and statistical analysis of collected variables

\begin{tabular}{|l|c|c|c|c|c||}
\hline \multicolumn{1}{|c|}{ Variable } & Variable symbol & Max. & Min. & Avg. & S.D. \\
\hline \hline Lane width in meters & LW & 3.65 & 3 & 3.5 & 0.22 \\
\hline Median width in meters & MW & 8 & 2 & 5.26 & 1.78 \\
\hline Lateral clearance in meters & LC & 3.6 & 1.2 & 1.84 & 0.41 \\
\hline Radius of curve in meters & $\mathrm{R}$ & 780 & 40 & 408.2 & 231.7 \\
\hline Deflection angle in degree & $\mathrm{DA}$ & 70.6 & 14.3 & 27.4 & 16.7 \\
\hline Superelevation \% & $\mathrm{e}$ & 12 & 2 & 4.6 & 3.5 \\
\hline Percentage of heavy vehicles & $\mathrm{HV}$ & 0.332 & 0.05 & 0.163 & 0.055 \\
\hline \hline
\end{tabular}

codes, and the statistical parameters are presented in Table 1.

\section{Traffic properties data}

During the data collection, manual traffic counting is carried out on the working days during the daylight hours from 7:00 am till 12.00 noon (five hours at each site) in clear weather and on dry pavements.

The position of counting is nearly at midpoint of the horizontal curve in one direction of the travel on the right lane only. The collected data involve the car class and the access time of car and are divided into 5-min periods. In every period, the number of cars is transformed into vehicles per hour.

In addition, the average travel speed of all vehicles (ATS) at each 5-min interval is calculated in $(\mathrm{km} / \mathrm{h})$ for each site. It is measured simply in the field, by taking a constant distance between 50 and $100 \mathrm{~m}$ throughout the length of each horizontal curve and the time in which the vehicles cut this distance is recorded. Next, the speed at each 5-min is calculated by dividing the constant distance per the average recorded times. Consequently, the right lane density in 5-min interval can be calculated by the following well-known Equation 1 in one direction of flow [2].

$D(R L)=\frac{q_{5 \min }(R L)}{A_{T S} S_{\min }}$

where

$D(R L)$-Density in right lane (vehicle per km per lane);

$q(R L)$-Traffic flow rate in right lane (vehicle per hour per lane); and

ATS -Average travel speed for all vehicles in right lane ( $\mathrm{km}$ per $\mathrm{hr}$ ).

The results of density are plotted versus flow rate as shown in Figure 2, which declares the relationship between flow rate and density at two curve sites. One curve site represents the divided four-lane and the other represents the divided six-lane. This relationship shows that the traffic stream represents clearly one condition of flow (steady state) at the two curve sites indicating that the case of bottleneck is formed on these sites. Therefore, these highways carry traffic volumes close to the capacity value. Therefore, the right lane capacity can be reached from reliable curve fitting of the traffic data at each site [3].

In addition, the percentage of heavy vehicle types (HV), Table 1, is detected at each site from the recorded manual counting. Heavy vehicles include semi-trucks, trucks and truck trailers that have at least one axle with dual wheels [16]. Finally, the effect of the different types of vehicles within a traffic stream is considered by converting the vehicles into passenger car units (PCU). GARBLT [16] specifies the PCU for each type of vehicles running on the Egyptian highways as shown in Table 2.

Table 2 - PCU for types of vehicles running on the Egyptian roads [16]

\begin{tabular}{||l|c||}
\hline \hline Type of vehicle & PCU \\
\hline \hline Motorcycles & 0.5 \\
\hline $\begin{array}{l}\text { Passenger cars, vans, mini-buses, } \\
\text { microbuses, and jeeps }(<5 \mathrm{~m})\end{array}$ & 1.0 \\
\hline Buses $(>8 \mathrm{~m})$ & 1.6 \\
\hline 2 axle long $(5-8 \mathrm{~m})$ & 1.9 \\
\hline 2 axle 6 tire $(5-8 \mathrm{~m})$ & 1.9 \\
\hline 3 axle single $(5-8 \mathrm{~m})$ & 1.9 \\
\hline 4 axle single $(>8 \mathrm{~m})$ & 2.6 \\
\hline 5 axle double $(>8 \mathrm{~m})$ & 2.6 \\
\hline 6 axle double $(>8 \mathrm{~m})$ & 2.6 \\
\hline 6 axle multi $(>8 \mathrm{~m})$ & 2.6 \\
\hline
\end{tabular}

\section{METHODOLOGY}

\subsection{Capacity determination methodology}

Three types of capacity are expressed beyond the scope here; capacity at the curve $(\mathrm{CH})$, capacity at the tangent (CT), and capacity loss between the curve and tangent (CLoss). 

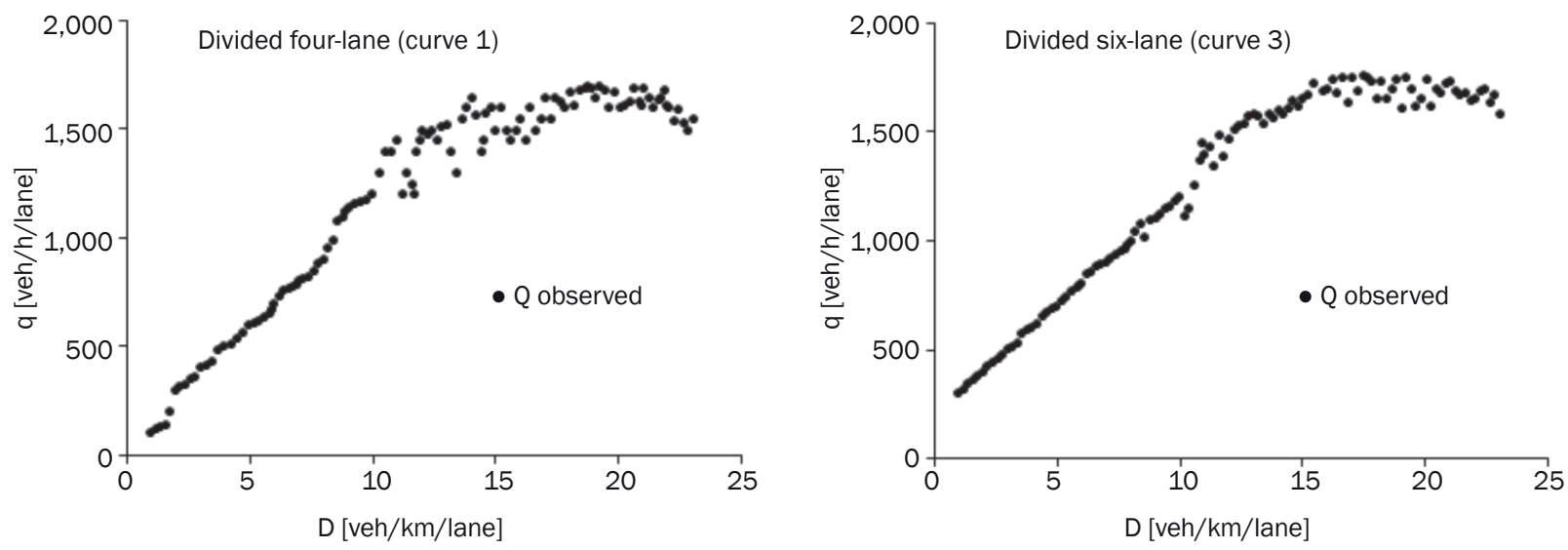

Figure 2 - Flow rate and density relationship on right lane for curves 1, 3

Capacity at curve $(\mathrm{CH})$

A direct-empirical procedure, [3] depending on the observed volumes, speeds and densities is employed to determine the capacity. In this method, the capacity can be measured either directly from the traffic data, if the road section forms a bottleneck, or estimated by extrapolating the steady flow observations. Investigation of Figure 2 shows that the capacity conditions are reached because these sites carry high traffic volumes close to the capacity value. However, the critical density can be derived directly by reliable curve fitting of the traffic data at each site.

The flow-density relationship has been described by van Arem et al. [17] and Minderhoud et al. [18] as having a quadratic form, Equation 2.

$q=\beta_{0}+\beta_{1} \cdot D+\beta_{2} \cdot D^{2}$

To achieve the bell shape of this relation, the sign of $\beta_{2}$ should be negative or zero and positive for $\beta_{1}$. It emphasized that the capacity of highway can be determined when the flow-density relationship takes the bell shape in which the critical density is attained at the crest point of the curve, where the capacity value occurs at the maximum value of flow. In the present study, the traffic capacity is determined by the method of square function, and the crest point of the curve produces the capacity.

\section{Capacity at tangent (CT)}

In this paper, the capacity at tangent (CT) is defined as the capacity at the same site properties without the horizontal curve. The capacity value is determined from the ANN model at the tangent section as derived in [14]. In his research, the tangent sections are divided into agricultural sections and desert sections and each of them will have a separate capacity model. To get the best capacity model for the agricultural sections, the coefficient of determination $\left(R^{2}\right)$ and root mean square error (RMSE) for the treated data set are
0.99 and 59.2, respectively, where for the desert sections, $\mathrm{R}^{2}$ and RMSR are 0.98 and 35.8 , respectively. These results are considered reliable for tangent capacity estimation and proper for use in the present paper.

\section{Capacity loss (CLoss)}

The capacity loss (CLoss) is defined as the capacity loss between the capacity at curve and that at the tangent. The horizontal curve surely forces the drivers to reduce their speed; consequently, the traffic flow will clearly decrease [4]. So, the capacity value of the horizontal curve is significantly lower than that at tangent under the same road and traffic properties.

\subsection{Non-traditional modelling procedure (ANNs)}

Broadly, the ANNs include 3 strata: the input, the hidden and the output. The input includes the independent factors and the output includes the capacity values. The ANNs ordinarily begin with randomized weights for whole neurons, when a favourable level performance is gained, training is stopped and the network utilizes these weights in the final model.

The adopted practice is acquired from Semeida [19], where the multi-layer perceptron (MLP) neural network paradigms grant the best achievement of all the paradigms. Therefore, the network can be easily applied in engineering problems due to the abundant learning algorithm extremely utilized in the MLP. Also, the ordinarily utilized learning algorithms in ANN implementations are the back propagation algorithm (BP), which is experienced in the present study, NeuroSolutions 7 [20]. The total sections are split into a training group and a testing group. The training group varies from $70 \%$ to $90 \%$ and the testing one from $10 \%$ to $30 \%$. The statistical Model parameters RMSE, $\|\delta\|$, and $\mathrm{R}^{2}$ are helpful for testing and training as well as all the data groups. 
So, many trials are executed to attain the appropriate percentage among training and testing groups that grants the best efficiency of capacity models. Furthermore, the over fitting can be precluded by randomizing the data prior to the training of the network to attain the best efficiency from both the training and the testing data. The statistical parameters of testing data must be perfect as training data, Tarefder et al. [21].

\section{RESULTS}

\subsection{Capacity determination on curves, tangents and capacity loss}

Due to the lot of calculations needed for capacity evaluation on the right lane on the horizontal curves (one direction of flow), the analysis is conducted for one curve of each road type: curve 1 presents divided four-lane and curve 3 presents divided six-lane.

On using the traffic data, the vehicle counts for each 5-min interval for each vehicle type are converted to 5-min flow rates $(q)$ in $\mathrm{PCU} / \mathrm{h}$. The average travel speed of each vehicle type in every 5-min period is determined in $\mathrm{km} / \mathrm{h}$. The densities are determined in veh/km by Equation 1. Consequently, the square equations among flow and density are standardized, and the equation coefficients for both cases are computed by Equations 3 and 4:

$$
\begin{aligned}
& q_{\text {curve } 1}(R L)=-150.27+180.17 \cdot D_{R L}-4.53 \cdot D_{R L}^{2} \\
& \text { (whereas, } \left.R^{2}=0.978\right) \\
& q_{\text {curve3 }}(R L)=18.83+164.58 \cdot D_{R L}-4.00 \cdot D_{R L}^{2} \\
& \text { (whereas, } \left.R^{2}=0.98\right)
\end{aligned}
$$

The coefficients of the model must have the suitable signs that grant the bell shape function; also their values must be considerably greater than zero at the 95\% level of confidence. Consequently, the critical

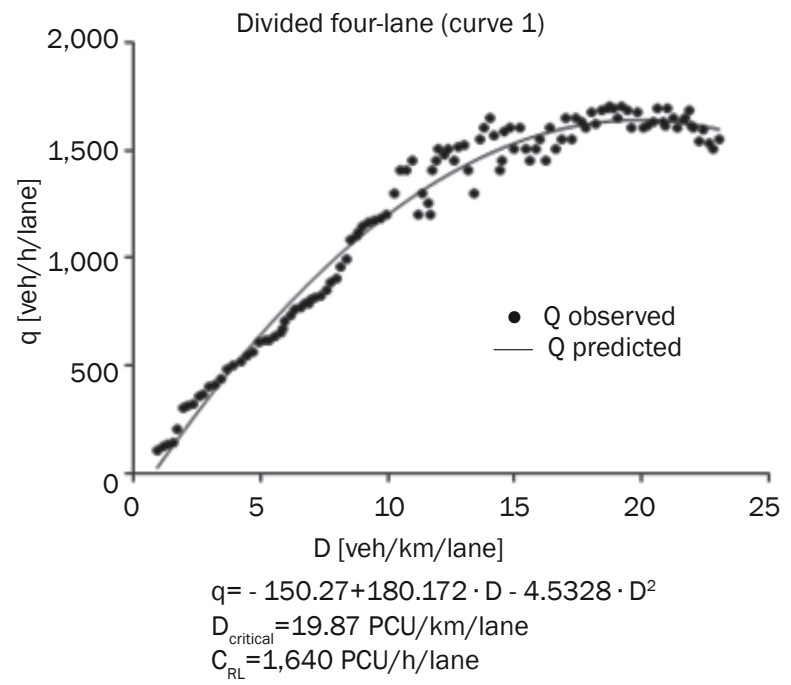

right lane density and capacity $\left(C_{R L}\right)$ value for the two curves are given as follows:

$$
\begin{gathered}
\text { - curve } 1\left(D_{\text {critical }}=19.87 \mathrm{PCU} / \mathrm{km} /\right. \text { lane, } \\
\left.C_{R L}=1,640 \mathrm{PCU} / \mathrm{h} / \text { lane }\right) \text {, and } \\
\text { - curve } 3\left(D_{\text {critical }}=20.57 \mathrm{PCU} / \mathrm{km} /\right. \text { lane, } \\
\left.C_{R L}=1,712 \mathrm{PCU} / \mathrm{h} / \text { lane }\right)
\end{gathered}
$$

Figure 3 shows the observed data, the fitting of all curves, and the derived CRL for the curves. The concluded models for whole conditions have the anticipated signs and the determined coefficients $\left(R^{2}\right)$ must be better than 0.8 . Table 4 clarifies the capacity values for all the 78 horizontal curves. The capacity at the tangent is calculated by the ANN model and the loss of capacity among the predetermined capacities is evaluated at every curved section. Table 3 presents the three types of capacity values at all the studied curves.

\subsection{Artificial Neural Network Models}

\subsubsection{Capacity at curves $(\mathrm{CH})$}

\section{Divided four-lane}

Correlation of the results of the ANN models shows that there are five characteristics extremely associated with $\mathrm{CH}$. These variables are put in the first stratum. One hidden stratum is utilized while the coveted variable $\mathrm{CH}$ is put in the last stratum with 55 used curves. The structure of the ANN paradigm is drawn in Figure 4. The neuron number in the second stratum is almost half the sum of the neurons in the first and the last stratum (three neurons), depending mostly on a reasonable awareness in this scope.

Utilizing the learning rule of momentum type and the adequate iteration number $=5,000$, is appropriate for rapid convergence of the case. Plentiful attempts are made to attain the best percentage among the training and testing sections that grant the superior model efficiency [15].

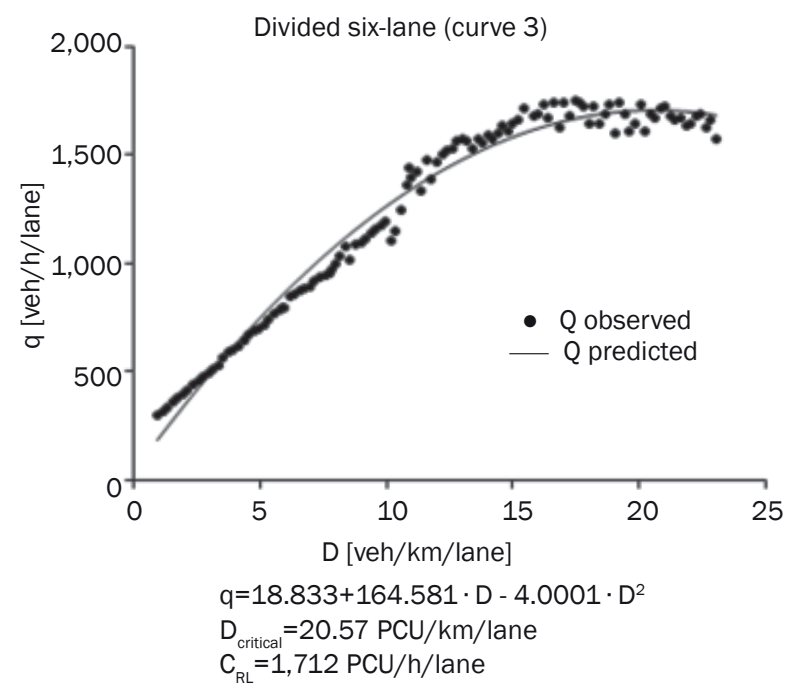

Figure 3 - Observed data, fitting curves, and the derived capacity at right lane for the curves 1, 3 
A. M. Semeida: Impact of Horizontal Curves and Percentage of Heavy Vehicles on Right Lane Capacity at Multi-lane Highways

Table 3 - Right lane capacity values and capacity loss at each site

\begin{tabular}{|c|c|c|c|c|c|c|c|}
\hline Curve No. & $\begin{array}{c}\text { Capacity } \\
\text { at curve } \\
\text { [PCU/h/lane] }\end{array}$ & $\begin{array}{c}\text { Capacity } \\
\text { at tangent } \\
{[\mathrm{PCU} / \mathrm{h} / \text { lane }]}\end{array}$ & $\begin{array}{l}\text { Capacity loss } \\
\text { [PCU/h/lane] }\end{array}$ & Curve No. & $\begin{array}{c}\text { Capacity } \\
\text { at curve } \\
\text { [PCU/h/lane] }\end{array}$ & $\begin{array}{c}\text { Capacity } \\
\text { at tangent } \\
{[\mathrm{PCU} / \mathrm{h} / \text { lane }]}\end{array}$ & $\begin{array}{l}\text { Capacity loss } \\
\text { [PCU/h/lane] }\end{array}$ \\
\hline 1 (4-lane) & 1,640 & 1,814 & 174 & 40 (4-lane) & 1,804 & 1,904 & 100 \\
\hline 2 (4-lane) & 1,561 & 1,648 & 87 & 41 (4-lane) & 1,748 & 1,846 & 98 \\
\hline 3 (6-lane) & 1,712 & 1,840 & 128 & 42 (4-lane) & 1,748 & 1,846 & 98 \\
\hline 4 (6-lane) & 1,636 & 1,840 & 204 & 43 (4-lane) & 1,748 & 1,846 & 98 \\
\hline 5 (6-lane) & 1,725 & 1,860 & 135 & 44 (4-lane) & 1,819 & 1,920 & 101 \\
\hline 6 (4-lane) & 1,786 & 1,908 & 122 & 45 (4-lane) & 1,815 & 1,917 & 102 \\
\hline 7 (4-lane) & 1,821 & 1,923 & 102 & 46 (4-lane) & 1,819 & 1,920 & 101 \\
\hline 8 (6-lane) & 1,684 & 1,847 & 163 & 47 (4-lane) & 1,711 & 1,806 & 95 \\
\hline 9 (6-lane) & 1,815 & 1,963 & 148 & 48 (4-lane) & 1,958 & 2,067 & 109 \\
\hline 10 (6-lane) & 1,746 & 1,874 & 128 & 49 (4-lane) & 1,848 & 1,951 & 103 \\
\hline 11 (6-lane) & 1,726 & 1,860 & 134 & 50 (4-lane) & 1,840 & 1,942 & 102 \\
\hline 12 (6-lane) & 1,684 & 1,847 & 163 & 51 (4-lane) & 1,848 & 1,951 & 103 \\
\hline 13 (6-lane) & 1,726 & 1,860 & 134 & 52 (4-lane) & 1,922 & 2,029 & 107 \\
\hline 14 (6-lane) & 1,765 & 1,874 & 109 & 53 (4-lane) & 1,848 & 1,951 & 103 \\
\hline 15 (6-lane) & 1,826 & 1,928 & 102 & 54 (4-lane) & 1,865 & 1,960 & 95 \\
\hline 16 (6-lane) & 1,730 & 1,870 & 140 & 55 (4-lane) & 1,840 & 1,942 & 102 \\
\hline 17 (6-lane) & 1,725 & 1,860 & 135 & 56 (4-lane) & 1,962 & 2,071 & 109 \\
\hline 18 (6-lane) & 1,711 & 1,845 & 134 & 57 (4-lane) & 1,943 & 2,070 & 127 \\
\hline 19 (6-lane) & 1,641 & 1,770 & 129 & 58 (4-lane) & 1,972 & 2,060 & 88 \\
\hline 20 (6-lane) & 1,806 & 1,948 & 142 & 59 (4-lane) & 1,848 & 1,951 & 103 \\
\hline 21 (6-lane) & 1,725 & 1,860 & 135 & 60 (4-lane) & 1,890 & 1,960 & 70 \\
\hline 22 (6-lane) & 1,740 & 1,880 & 140 & 61 (4-lane) & 1,870 & 1,945 & 75 \\
\hline 23 (6-lane) & 1,826 & 1,928 & 102 & 62 (4-lane) & 1,718 & 1,814 & 96 \\
\hline 24 (6-lane) & 1,746 & 1,883 & 137 & 63 (4-lane) & 1,837 & 1,939 & 102 \\
\hline 25 (6-lane) & 1,710 & 1,890 & 180 & 64 (4-lane) & 1,850 & 1,950 & 100 \\
\hline 26 (6-lane) & 1,750 & 1,870 & 120 & 65 (4-lane) & 1,860 & 1,945 & 85 \\
\hline 27 (6-lane) & 1,739 & 1,836 & 97 & 66 (4-lane) & 1,830 & 1,940 & 110 \\
\hline 28 (6-lane) & 1,702 & 1,797 & 95 & 67 (4-lane) & 1,840 & 1,942 & 102 \\
\hline 29 (6-lane) & 1,706 & 2,191 & 485 & 68 (4-lane) & 1,837 & 1,958 & 121 \\
\hline 30 (6-lane) & 1,706 & 2,191 & 485 & 69 (4-lane) & 1,831 & 1,950 & 119 \\
\hline 31 (6-lane) & 1,748 & 1,846 & 98 & 70 (4-lane) & 1,840 & 1,942 & 102 \\
\hline 32 (6-lane) & 1,760 & 1,850 & 90 & 71 (4-lane) & 1,844 & 1,939 & 95 \\
\hline 33 (6-lane) & 1,770 & 1,870 & 100 & 72 (4-lane) & 1,837 & 1,930 & 93 \\
\hline 34 (6-lane) & 1,730 & 1,865 & 135 & 73 (4-lane) & 1,819 & 1,920 & 101 \\
\hline 35 (6-lane) & 1,720 & 1,830 & 110 & 74 (4-lane) & 1,846 & 1,925 & 79 \\
\hline 36 (6-lane) & 1,778 & 1,877 & 99 & 75 (4-lane) & 1,839 & 1,935 & 96 \\
\hline 37 (6-lane) & 1,748 & 1,846 & 98 & 76 (4-lane) & 1,829 & 1,949 & 120 \\
\hline 38 (6-lane) & 1,778 & 1,877 & 99 & 77 (4-lane) & 1,748 & 1,846 & 98 \\
\hline 39 (6-lane) & 1,748 & 1,846 & 98 & 78 (4-lane) & 1,718 & 1,814 & 96 \\
\hline
\end{tabular}


The statistical parameters of the superior attempt for training, testing, and both of the groups are produced in Table 4 . These are obtained by splitting the sections into training group that has 44 sections (80\% of the curves), and testing group that has 11 sections (20\% of the curves).

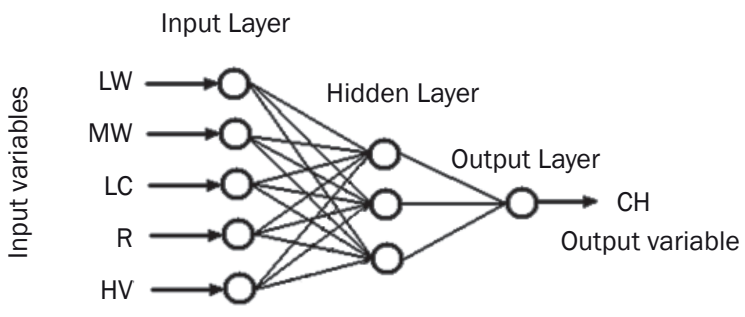

Figure 4 - MLP network architecture of $\mathrm{CH}$ model

In view of evaluating the significance of all independent factors, the common effect (sensibility around the average or standard deviation), is calculated depending on the trained weights of the network. For each variable, if the preceding value is greater than others, this implies that its influence on the following variable $\mathrm{CH}$ is greater than the others. Figure 5 offers the sensibility of every independent variable in the chosen model. It is indicated that the most effective factor on the $\mathrm{CH}$ is $\mathrm{HV}$, pursued by $\mathrm{LW}$ and $\mathrm{R}$. The relationships between the variables are shown in Figure 5. This figure shows that the $\mathrm{CH}$ increases with the increment of $\mathrm{R}$ and $\mathrm{LW}$ and reduction of $\mathrm{HV}$.

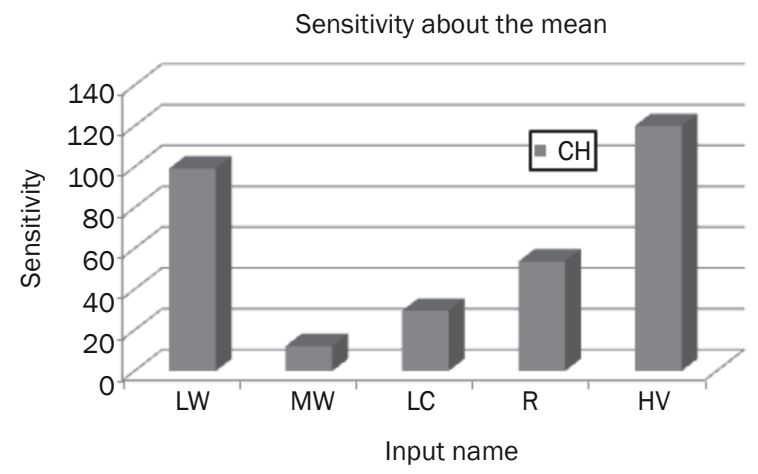

Network output(s) for varied input LW

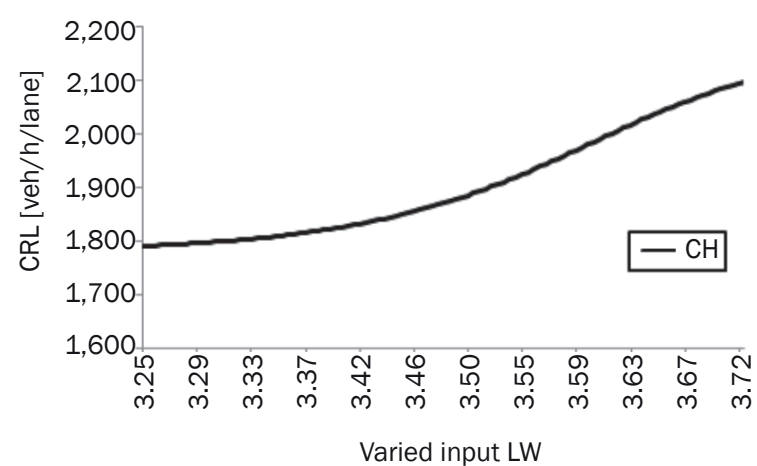

\section{Divided six-lane}

There are five characteristics extremely associated with $\mathrm{CH}$ in the input stratum. One hidden layer is utilized and one coveted variable $\mathrm{CH}$ is put in the last stratum with 23 employed curves. The performances of the best attempt for training, testing, and overall data set are listed in Table 4. In this trial, where the curves are divided into the training data set that has 19 curves (83\% of all sites), and testing data set that has 4 curves ( $17 \%$ of all sites). Figure 6 shows the sensitivity of each explanatory variable in the selected model. It is found that the most influential variable on $\mathrm{CH}$ is $\mathrm{R}$, followed by HV. The relationships between each effective variable and $\mathrm{CH}$ are shown in Figure 6. It indicates that $\mathrm{CH}$ increases with the increase of $\mathrm{R}$ and reduction of $\mathrm{HV}$.

\subsection{Capacity Loss (CLoss)}

\section{Divided four-lane}

The performances of the best trial for training, testing, and overall data set are presented in Table 4. The sensitivity analysis and the relationships between each effective input variable and CLoss are shown in Figure 7. In this case, the impact of LC is so small on CLoss that it can be neglected. Therefore, it is removed from the sensitivity diagram. The diagrams indicate that the CLoss decreases with the increment of $\mathrm{R}$ and $\mathrm{LW}$, and increases with the increment of HV.

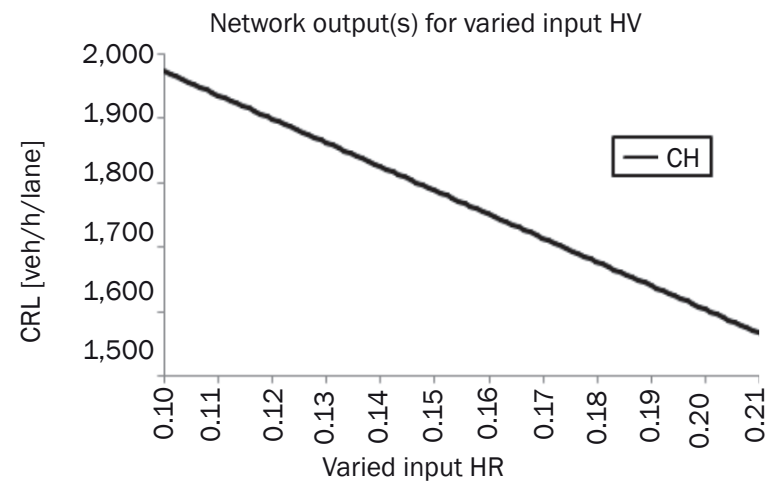

Network output(s) for varied input R

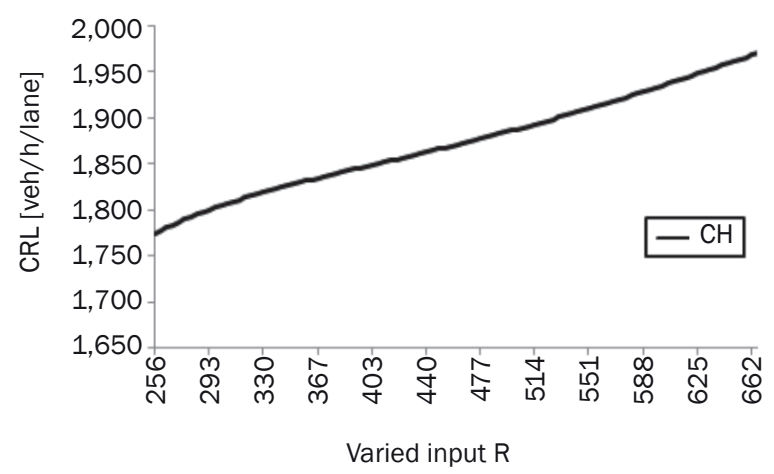

Figure 5 - Sensitivity and $\mathrm{CH}$ versus effective variables relationships (divided four-lane) 

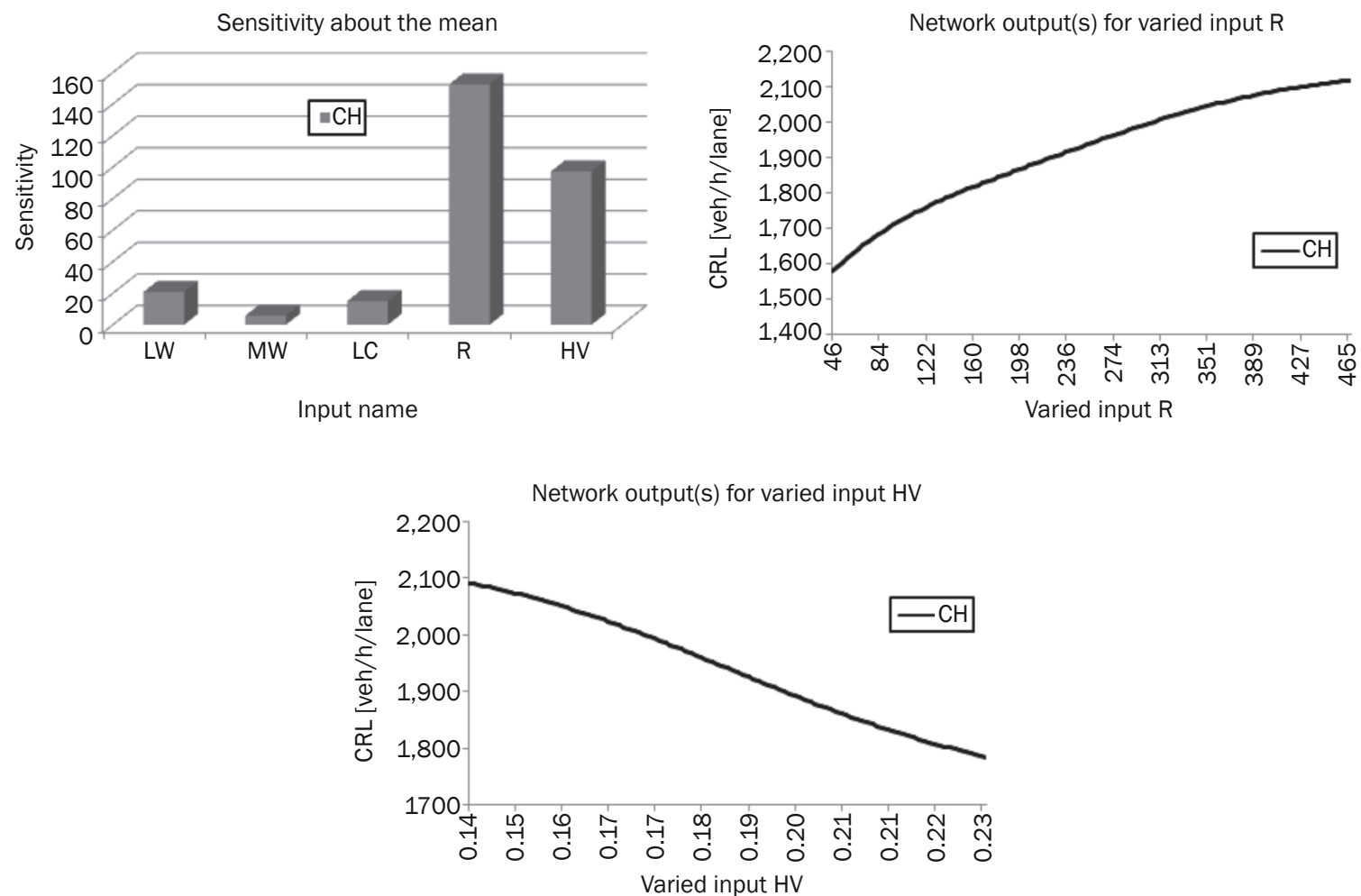

Figure 6 - Sensitivity and $\mathrm{CH}$ versus effective variable relationships (divided six-lane)

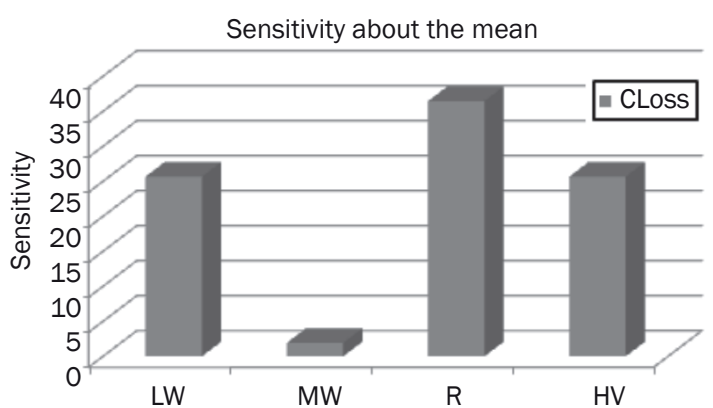

Input name

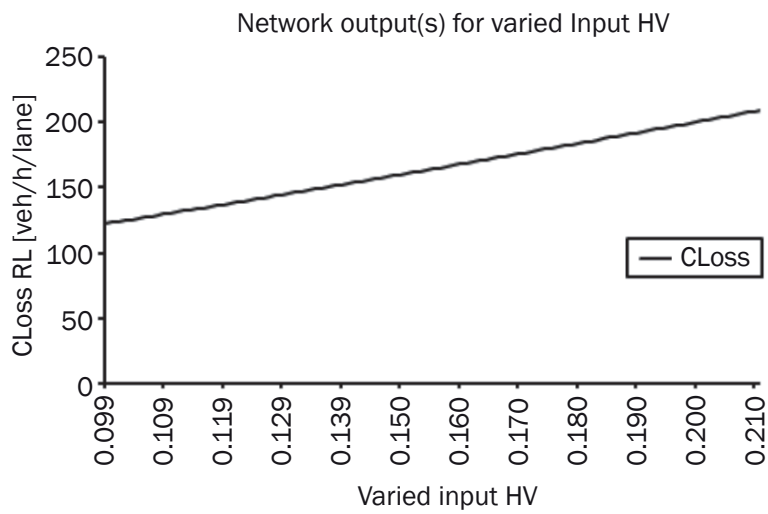

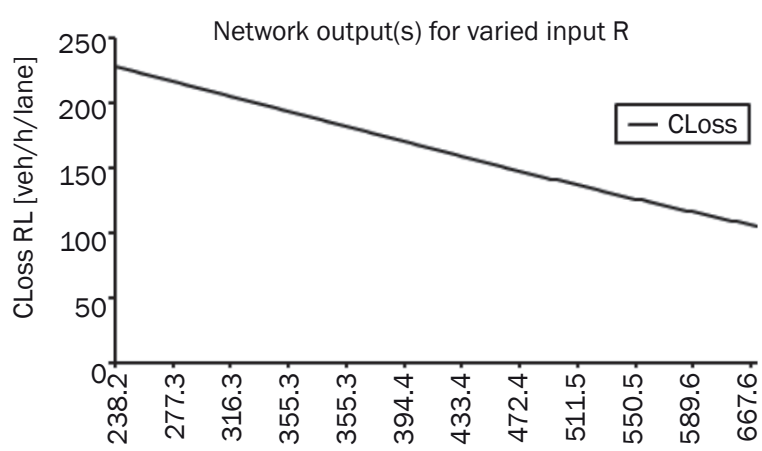

Varied input $\mathrm{R}$

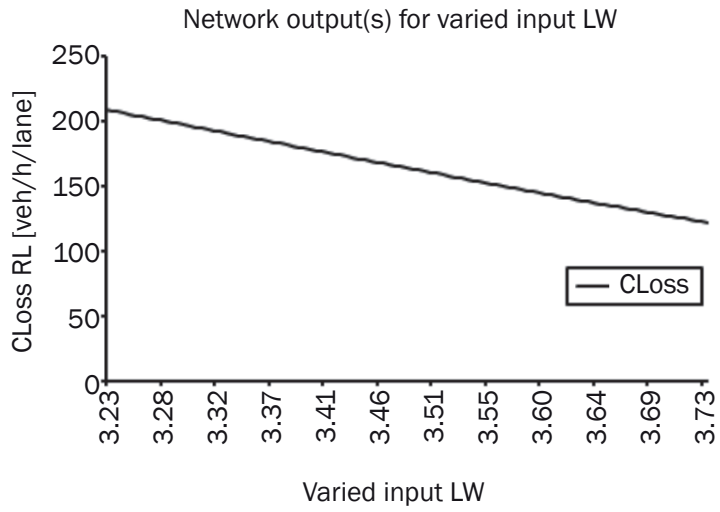

Figure 7 - Sensitivity and CLoss versus effective variable relationships (divided four-lane) 


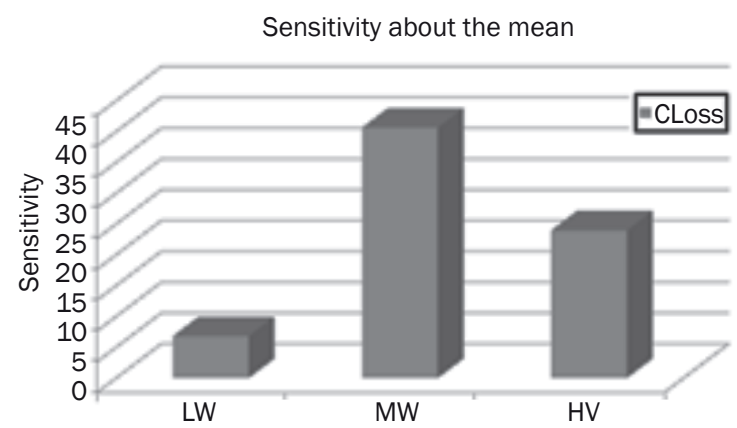

Input name

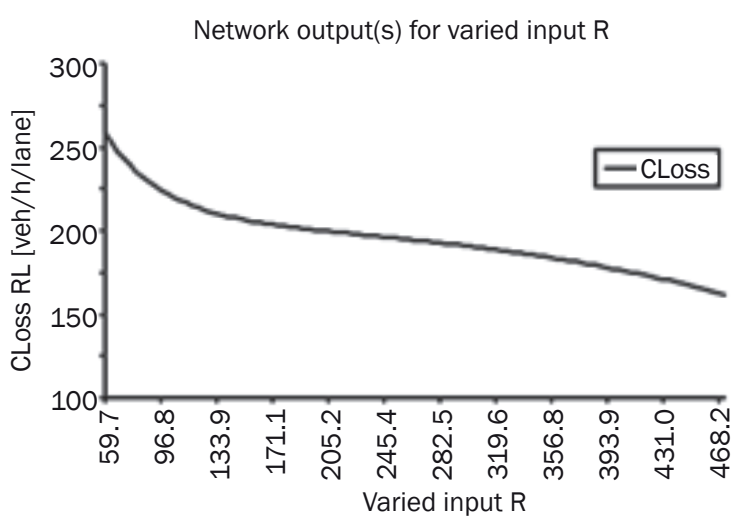

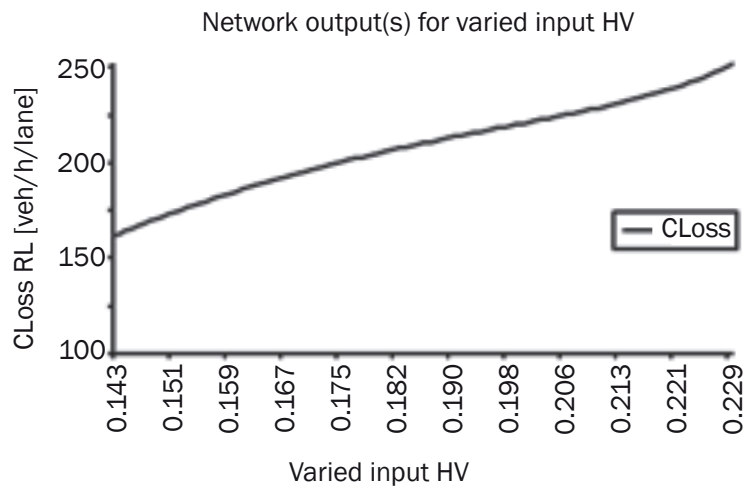

Figure 8 - Sensitivity and CLoss versus effective variable relationships (divided six-lane)

Table 4 - Performance for the best trials of all ANN capacity model

\begin{tabular}{||c|c|c|c|c|c|c|c|c||}
\hline \multirow{4}{*}{} & \multicolumn{4}{|c|}{ Divided four-lane } & \multicolumn{4}{c|}{ Divided six-lane } \\
\cline { 2 - 11 } & $\begin{array}{c}\text { Perfor- } \\
\text { mance }\end{array}$ & $\begin{array}{c}\text { Training } \\
\text { samples }\end{array}$ & $\begin{array}{c}\text { Testing } \\
\text { samples }\end{array}$ & $\begin{array}{c}\text { Overall } \\
\text { Model }\end{array}$ & $\begin{array}{c}\text { Perfor- } \\
\text { mance }\end{array}$ & $\begin{array}{c}\text { Training } \\
\text { samples }\end{array}$ & $\begin{array}{c}\text { Testing } \\
\text { samples }\end{array}$ & $\begin{array}{c}\text { Overall } \\
\text { Model }\end{array}$ \\
\hline \hline \multirow{3}{*}{$\mathrm{CH}$} & $\mathrm{R}^{2}$ & 0.966 & 0.98 & 0.967 & $\mathrm{R}^{2}$ & 0.994 & 0.96 & 0.989 \\
\cline { 2 - 11 } & $\mathrm{RMSE}$ & 16.06 & 10.75 & 15.15 & $\mathrm{RMSE}$ & 3.46 & 8.34 & 4.69 \\
\cline { 2 - 11 } & $\|\delta\|$ & 0.027 & 0.01 & 0.027 & $\|\delta\|$ & 0.037 & 0.01 & 0.01 \\
\hline \multirow{3}{*}{ CLoSS } & $\mathrm{R}^{2}$ & 0.991 & 0.958 & 0.984 & $\mathrm{R}^{2}$ & 0.993 & 0.871 & 0.99 \\
\cline { 2 - 11 } & $\mathrm{RMSE}$ & 1.48 & 3.17 & 1.94 & $\mathrm{RMSE}$ & 9.49 & 13.13 & 10.21 \\
\cline { 2 - 11 } & $\|\delta\|$ & 0.022 & 0.04 & 0.028 & $\|\delta\|$ & 0.032 & 0.129 & 0.04 \\
\hline \hline
\end{tabular}

Divided six-lane

Similar results are reached as the divided fourlane. The performances of the best trial for training, testing, and overall data set are presented also in Table 4 . The sensitivity analysis and the relationships between each effective input variable and CLoss are shown in Figure8. The variables $\mathrm{LC}$ and MW have a very low effect on CLoss. So, no need to present them in the sensitivity analysis. The diagrams indicate that the CLoss decreases with the increment of $\mathrm{R}$ and increases with the increment of HV.

\section{DISCUSSION}

The previous results will be explained and discussed in this section.
The results of the best ANN models for divided four-lane indicate that the increase of HV from $10.0 \%$ to $21 \%$ leads to a considerable reduction of $\mathrm{CH}$ from $1,980 \mathrm{veh} / \mathrm{h} /$ lane to $1,570 \mathrm{veh} / \mathrm{h} /$ lane. The increase of LW by nearly $0.5 \mathrm{~m}$ leads to a great improvement in $\mathrm{CH}$ value by 300 veh/h/lane. The increase of $\mathrm{R}$ by nearly $400 \mathrm{~m}$ leads to a great development in $\mathrm{CH}$ by $200 \mathrm{veh} / \mathrm{h} /$ lane.

Furthermore, for divided four-lane: the increase of $\mathrm{R}$ from $238 \mathrm{~m}$ to $668 \mathrm{~m}$ decreases the CLoss from 225 veh/h/lane to $100 \mathrm{veh} / \mathrm{h} /$ lane, while the increase of HV from $9.9 \%$ to $21 \%$ leads to an increase of CLoss from 125 veh/h/lane to $210 \mathrm{veh} / \mathrm{h} /$ lane. Finally, the increase of LW from $3.23 \mathrm{~m}$ to $3.73 \mathrm{~m}$ leads to a 
decrease of CLoss from 210 veh/h/lane to 125 veh/h/lane.

The results of best ANN models for divided six-lane indicate that the increase of $\mathrm{R}$ from $46 \mathrm{~m}$ to $465 \mathrm{~m}$ leads to a great improvement in $\mathrm{CH}$ value from 1,600 veh/h/lane to $2,100 \mathrm{veh} / \mathrm{h} /$ lane. In addition, the increase of HV from $14.0 \%$ to $23.0 \%$ leads to a considerable reduction of $\mathrm{CH}$ from $1,800 \mathrm{veh} / \mathrm{h} /$ lane to 2,100 veh/h/lane.

Also, for the divided six-lane: the increase of $\mathrm{R}$ from $60 \mathrm{~m}$ to $468 \mathrm{~m}$ leads to a decrease of CLoss from $260 \mathrm{veh} / \mathrm{h} /$ lane to $160 \mathrm{veh} / \mathrm{h} /$ lane. In addition, the increase of HV from $14.3 \%$ to $22.9 \%$ leads to an increase of CLoss from 165 veh/h/lane to 250 veh/h/lane.

\section{CONCLUSION}

The present study examines the effectiveness of road geometry and traffic properties on the right lane capacity at horizontal alignment for the Egyptian major highways. Two types of capacity are modelled; capacity at curves and capacity loss between curves and tangents. The most important findings are given here below:

\section{For divided four-lane:}

Generally, as HV increases, especially on horizontal curve, its impact on vehicle speed becomes greater. Therefore, $\mathrm{CH}$ clearly increases chiefly in the right lane.

Moreover, the horizontal curves that have greater LW and $R$ encourage the drivers to increase their speed on them than with smaller values. Thus, the greater LW and R improve capacity on horizontal curves.

As both $\mathrm{R}$ and LW properties are greater, the impact of the horizontal curve on vehicle speed gradually diminishes. Subsequently, CLoss between tangent and curve decreases. On the contrary, CLoss rises with the increment of HV. As HV increases, especially on horizontal curve, its impact on vehicle speed becomes greater. Therefore, CLoss clearly increases.

\section{For divided six-lane:}

The horizontal curves that have a greater $\mathrm{R}$ encourage the drivers to increase their speed on them. Consequently, the capacity improves. Also, HV have an adverse effect on the right lane capacity.

The impact of LW on CLoss is negligible due to wider road width than divided four-lane.

However, the reached outputs are so substantial for the Egyptians road responsible due to the following:

a) They enable computation of the capacity at different curved sections and tangents as well as the capacity loss.

b) This research is an important step to derive a separate model which only concerns the capacity loss between horizontal curve and tangent. The application of this model is very useful and reliable. c) Now, on Egyptian multi-lane highways, no need to obtain capacity at curve and tangent to reach capacity loss between both. Just apply this CLoss best ANN model to obtain it.

d) The reached outputs can enhance the traffic capability hereafter.

e) The reached outcomes can be utilized to improve the highway design and achieve a remarkable move to the beginning of the Egyptian highway design guide.

f) Encourage searching the influence of the pavement distress on the capacity at the Egyptian facilities which is considered to be a major goal in the future.
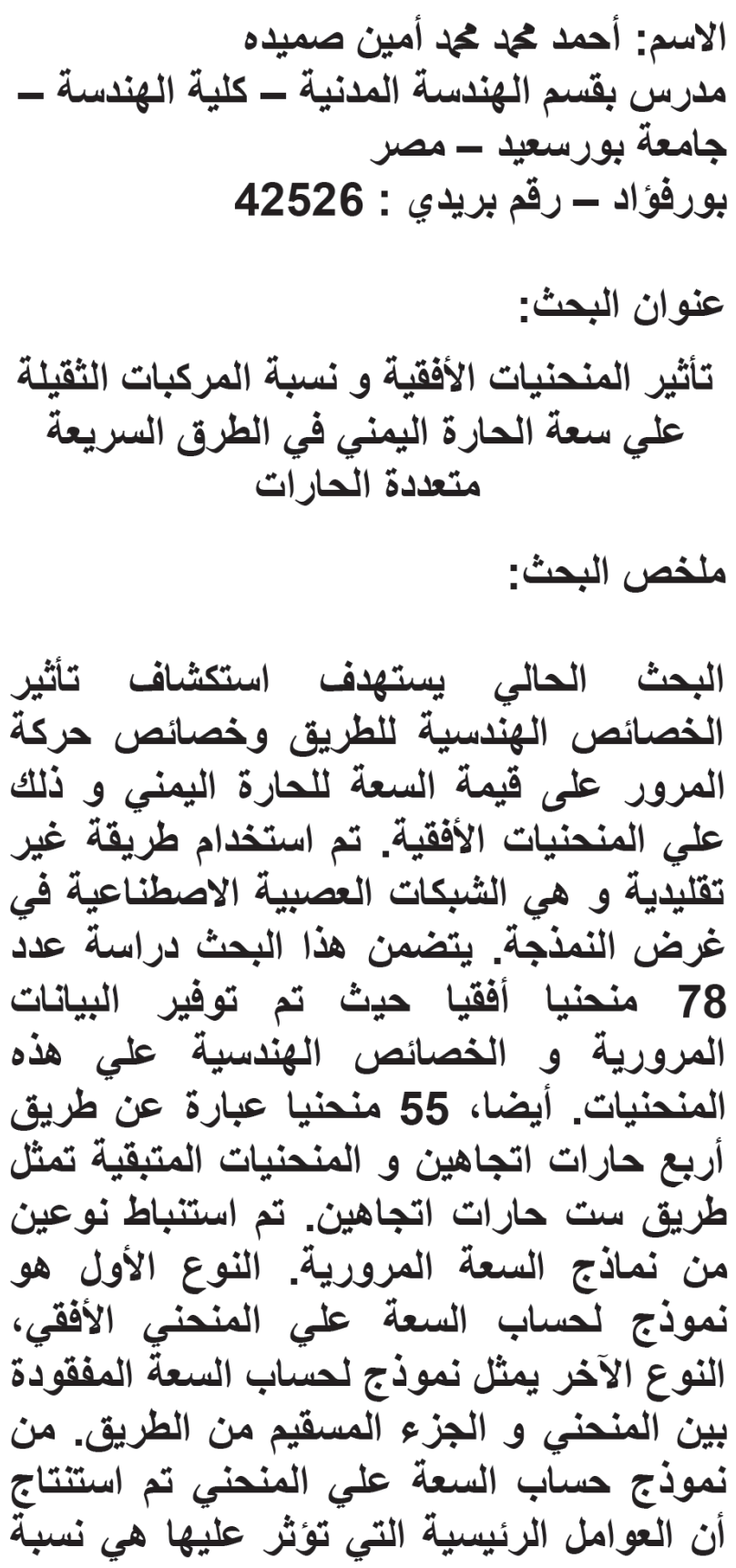


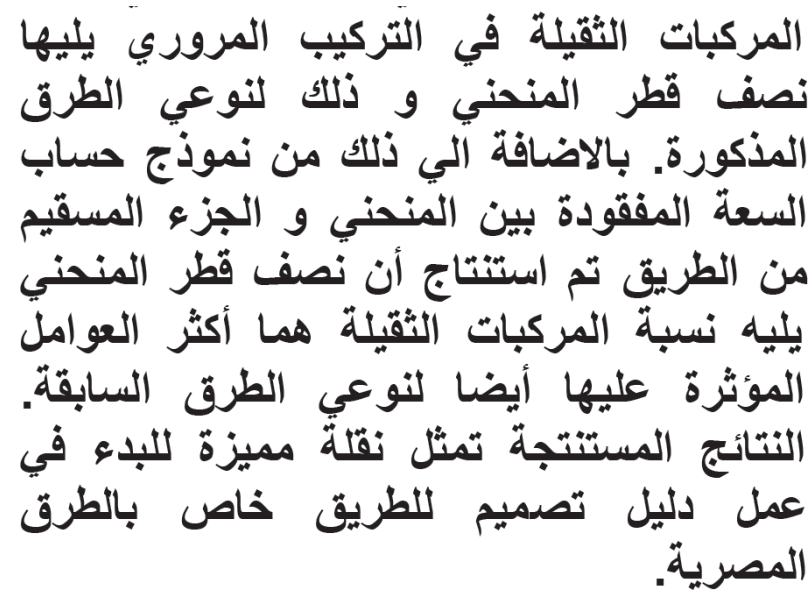

\section{REFERENCES}

[1] Kerner BS. Three phase Traffic Theory and Highway Capacity. Physica A. 2004;333:379-450. doi: 10.1016/ j.physa.2003.10.017

[2] Transportation Research Board. Highway Capacity Manual. $4^{\text {th }}$ ed. Washington, DC: Transportation Research Board, National Research Council; 2010

[3] Minderhoud M, Botma H, Bovy P. Assessment of roadway capacity estimation methods. Transport Res Rec. 1997;1572:59-67. doi: 10.3141/1572-08

[4] Hashim IH, Abdel-Wahed TA. Effect of Highway Geometric Characteristics on Capacity Loss. TransportSys Eng \& Inf Tech. 2012;12(5):65-75. doi: 10.1016/S1570-6672(11)60223-7

[5] Iwasaki M. Empirical Analysis of Congested Traffic Flow Characteristics and Free Speed Affected by Geometric Factors on an Intercity Expressway. Transport Res Rec. 1997;1320:242-250. Available from: http://trid.trb. org/view.aspx?id=365607

[6] Ibrahim AT, Hall FL. Effect of Adverse Weather Conditions on Speed-Flow- Occupancy Relationships. Transport Res Rec. 1994;1457:184-191. Available from: http://trid.trb.org/view.aspx?id=425358

[7] Shankar V, Mannering F. Modeling the Endogeneity of Lane-Mean Speeds and Lane- Speed Deviations: A Structural Equations Approach. Trans Res Part A. 1998;32: 311-322. doi: 10.1016/S09658564(98)00003-2

[8] Bang KL. Indonesian Highway Capacity Manual. Department of Public Works.Jakarta, Indonesia: Directorate General Highways; 1997.

[9] Yang X, Zhang N. The marginal decrease of lane capacity with the number of lanes on highway. Proceedings of the Eastern Asia Society for Transportation Studies. 2005;5:739-749. Available from: http://www.easts. info/on-line/proceedings_05/739.pdf
[10] Ben-Edigbe J, Ferguson N. Extent of capacity loss resulting from pavement distress. Proceedings of the Institution of Civil Engineers: Transport. 2005;158:2732. Available from: http://dx.doi.org/10.1680/ tran.2005.158.1.27

[11] Velmurugan S, Madhu E, Ravinder K, Sitaramanjaneyulu K, Gangopadhyay S. Critical evaluation of roadway capacity of multi-lane high speed corridors under heterogeneous traffic conditions through traditional and microscopic simulation models. Ind. Roads Cong. 2010;556: 235-264. Available from: http://www. crridom.gov.in/sites/default/files/irc-paper-no.566paper-given-bihar-pwd-medal-by-irc.pdf

[12] Arasan V, Arkatkar S. Derivation of Capacity Standards for Intercity Roads Carrying Heterogeneous Traffic using Computer Simulation. Procedia. 2011;16:218229. doi: 10.1016/j.sbspro.2011.04.444

[13] García A, Torres AJ, Romero MA, Moreno AT. Traffic Microsimulation Study to Evaluate the Effect of Type and Spacing of Traffic Calming Devices on Capacity. Procedia. 2011;16:270-281. doi: 10.1016/j.sbspro.2011.04.449

[14] Semeida AM. New Models to Evaluate the Level of Service and Capacity for Rural Multi-Lane Highways in Egypt. Alex Eng J. 2013;52(3):455-466. doi: org/10.1016/j.aej.2013.04.003

[15] Semeida AM. Derivation of level of service by artificial neural networks at horizontal curves: a case study in Egypt. Eur Trans Res Rev. 2015;7(1):1-12. doi: 10.1007/s12544-014-0152-2

[16] General Authority of Roads, Bridges and Land Transport. Cairo, Egypt: "GARBLT", System of Traffic counting data; 2009.

[17] Van Arem B, van der Vlist MJM, de Ruiter JCC, et al. Design of the Procedures for Current Capacity Estimation and Travel Time and Congestion Monitoring. DRIVE-11, Project V2044. Commission of the European Communities; 1994.

[18] Minderhoud M, Botma H, Bovy P. Roadway capacity using the product-limit approach. $77^{\text {th }}$ Annual Meeting of the Transportation Research Board. Washington D.C; 1998.

[19] Semeida AM, El-Shabrawy M. Impact of multi-lane pavement condition on passenger car traffic. Građevinar. 2016;68(8):635-644. doi: 10.14256/JCE.1466.2015

[20] "NeuroSolutions 7".Gainesville, Florida: NeuroDimension, Inc.; 2014.

[21] Tarefder RA, White L, Zaman M. Neural Network Model for Asphalt Concrete Permeability.Mat Civ Eng. 2005;17:19-27. Available from: http://dx.doi. org/10.1061/(ASCE)0899-1561 